\title{
Fragile X Syndrome: A Rare Case of a Female Carrier Exhibiting the Phenotypic Spectrum of Disease Features
}

ISSN: 2639-0531

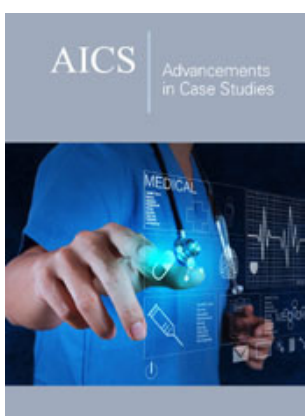

*Corresponding author: Yan Leyfman, Penn State College of Medicine, USA

Submission: 眥 March 09, 2020

Published: 悳 March 13, 2020

Volume 2 - Issue 3

How to cite this article: Yan Leyfman, Katherine Curci. Fragile X Syndrome: A Rare Case of a Female Carrier Exhibiting the Phenotypic Spectrum of Disease Features. Adv Case Stud.2(3). AICS.000540.2020. DOI: 10.31031/AICS.2020.02.000540

Copyright@ Yan Leyfman, This article is distributed under the terms of the Creative Commons Attribution 4.0 International License, which permits unrestricted use and redistribution provided that the original author and source are credited.

\author{
Yan Leyfman*1 and Katherine Curci ${ }^{2}$ \\ ${ }^{1}$ Penn State College of Medicine, USA \\ ${ }^{2}$ Department of Family and Community Medicine, USA
}

\begin{abstract}
Fragile X Syndrome is an X-linked recessive mutation in the Fragile X Mental Retardation 1 (FMR1) gene that although more common in males, can affect females who act as carriers and present with less severe symptoms along a spectrum of phenotypes contingent on the number of CGG trinucleotide repeats. Although there are few studies on carriers in the literature, the ones present tend to showcase a minority of the potential presentations of this condition. Here we present a case of a carrier female diagnosed in her teenage years who exhibits a wide spectrum of disease manifestations, including depression, anxiety, addiction, anorexia, substance abuse and premature ovarian failure. Despite being lost to follow-up from her primary care provider and battling addiction, the patient was largely in normal health. This case demonstrates the importance of early diagnosis and intervention to prevent the associated disease manifestations and concurrent co-morbidities from worsening.
\end{abstract}

Keywords: Fragile X Syndrome carrier; Depression; Substance abuse; Premature ovarian failure; Anorexia

\section{Introduction}

Fragile X Syndrome is an X-linked recessive mutation in the Fragile X Mental Retardation 1 (FMR1) gene that results in CGG trinucleotide repeats in the 5' untranslated arm of the FMR1 gene resulting in methylation that silences and/or reduces gene expression. The condition that manifests along a spectrum of symptoms depending on the number of repeats, where a premutation (defined as 55 to 200 CGG repeats) presents with less severe symptoms compared to a full mutation ( $>200$ repeats). The full mutation tends to be more male predominant (85\%), while the premutation tends to affect females more who are carrier of this condition [1]. The premutation condition is divided into two subtypes- Fragile X-associated Primary Ovarian Insufficiency (FXPOI) and Fragile X-associated Tremor/ Ataxia Syndrome (FXTAS) [2]. Although both conditions manifest with psychiatric conditions, they possess unique features on presentation where FXPOI occurs in $20 \%$ of female carriers and presents with menopause before the age of 40 , while FXTAS occurs in $16 \%$ of females and presents with neurological symptoms, including intention tremors, ataxic gait, autonomic dysfunction, neuropathy, and Parkinsonism [3]. Although the psychiatric disorders common to both conditions tend to be depression and/or anxiety, they can also include psychosis and memory and executive function deficits in more advanced cases [4]. Studies have shown that in FXTAS the psychiatric symptoms manifest before the neurological conditions [5]. Studies have also noted an association between the cognitive decline in carriers of this mutation and increased substance abuse that patients fail to acknowledge as abnormal [6,7]. Due to the dearth of Fragile X carrier cases in the literature, there are few observed cases that can document the extent of this condition. Herein, we present a case of female adult carrier who has uniquely displayed the spectrum of systemic manifestations since menarche.

\section{Case Presentation}

The patient is a 31-year-old female who came to one of Hershey Medical Center's outpatient Family Medicine Clinics to re-establish care after being lost to follow-up for almost a decade. She explained that she lives in a family of 3 siblings where her mother is carrier of the FMR1 gene. However, the patient did not find out that she was as a carrier as well until her early teenage years as she was largely asymptomatic until then. She noted that because 
she was healthy, she largely avoided physicians except when very ill. The patient noted that she began menarche at the age of 13 but presented with irregular cycles followed by menopause by the time she was 14. Further work-up showed that she had premature ovarian failure (POF) due to elevated Follicle Stimulating Hormone (FSH) levels. Genetic testing confirmed her FMR1 carrier status, but at that time, the patient had difficulty grasping the extent of this condition due to her concern for POF and its ramifications on the rest of her life. As a result, the patient never inquired about the extent of her mutation. According to the patient, physicians attributed her early onset POF to her carrier status and she had a received Essure placed at their recommendation. The patient noted that this was emotionally devastating, especially since her twin sister, who is also a carrier, was able to have children through in vitro fertilization.

Shortly thereafter, the patient noted that she turned to drugs as an outlet. Due to a history of constipation, the patient developed an addiction to Ducalax. The patient noted that extensive use of this mediation resulted in her developing anorexia in high school. She only began to seek help for this condition at the age of 23 when she enrolled into an eating disorder's clinic in 2012. The patient noted improvement and was off laxatives for a period of 3 months but relapsed shortly thereafter. For the past 3 years, she noted that she has been taking 20 laxatives each night. Despite laxative use, the patient noted that she eats normally, but does experience occasional symptoms of dizziness, lightheadedness, and nausea. In addition, the patient noted that she has been an alcoholic from 2006-2012. Although she initially only drank several shots, this addiction progressed to the point where she was drinking until blacking out almost daily. In 2012, the patient decided to seek help and was admitted into an inpatient facility, but treatment was unsuccessful. The patient noted that she went homeless for a short time period and then turned to Alcoholics Anonymous, which she credits with helping her get back to normalcy. The patient noted that she has been sober since 2012 and continues to be actively involved with Alcoholics Anonymous. Patient noted that because her sister was not an addict, she grew to be 6' tall with the same thin body frame as the patient, who was only 5' 4". Additionally, she was able to have a child with the help of in vitro fertilization.

The patient noted that she had been diagnosed in the past with depression and anxiety but was unable to recall at what age. She noted that she had always struggled with these symptoms, but it was only in the past 3.5 years did she seek therapy and medical intervention. She was prescribed $100 \mathrm{mg}$ Sertraline and started seeing a therapist, which she noted helped to control her symptoms. This was confirmed by a normal mood and affect during her visit to re-establish care and by objective testing with GAD-7=1 and PHQ-9=5. The patient has three siblings-two younger brothers and one twin sister; she and her twin sister are the oldest. Her family history is significant for Asperger's Syndrome (youngest brother), heroin addiction (middle brother), Premature Ovarian Failure (twin sister), hypertension (father), breast cancer (maternal and paternal grandmothers), and osteoporosis (multiple maternal and paternal family members). The patient noted that her mother was also a FMR1 gene carrier but was largely asymptomatic.

The patient is up to date on immunizations, preventative screenings, and vaccinations. She denied being sexually active. Her social history is significant for an occupation as a Human Resources manager. She noted that in her spare time, she enjoys using tanning salons and doing yoga for stress relief. Vital signs from this patient were within normal limits except for hypotension and a significantly low BMI (Table 1). A full physical examination was performed and was within normal limits except for the patient's cachexia. She was without acute distress and hyperreflexia 3+ bilaterally in her upper and lower extremities. On the patient's fair skin, an increased number of nevi were noted. Basic labs consisting of a complete metabolic panel, complete blood count with platelets, and TSH were drawn. They were within normal limits except for a slightly elevated Creatinine of 1.06 (Table 2).

Table 1: Vital signs from initial encounter.

\begin{tabular}{|c|c|c|}
\hline & Patient Values & Normal Range \\
\hline Temperature (oC) & 36.9 & 37 o C \\
\hline BP & $82 / 46 ; 102 / 80^{*}$ & $90-120 / 60-80$ \\
\hline Pulse & 96 & $60-100$ beats/minute \\
\hline RR & 14 & $12-20$ breaths $/$ minute \\
\hline BMI & 16.59 & \\
\hline Weight $(\mathrm{kg})$ & 44.9 & \\
\hline Height $(\mathrm{cm})$ & 164.6 & \\
\hline
\end{tabular}

* Note: BP was retaken toward the end of the encounter.

Table 2: Lab results from initial encounter.

\begin{tabular}{|c|c|c|}
\hline & Patient Values & Normal Range \\
\hline WBC & 6.96 & $4,500-11,000$ per $\mu \mathrm{l}$ \\
\hline $\mathrm{RBC}$ & 4.56 & 4.2-5.4 million cells $/ \mathrm{mcL}$ \\
\hline $\mathrm{Hgb}$ & 13.9 & $12.0-16.0 \mathrm{~g} / \mathrm{dL}$ \\
\hline Hct & 43 & $37-48 \%$ \\
\hline $\mathrm{MCV}$ & 94.3 & 80-100fL \\
\hline $\mathrm{MCH}$ & 30.5 & $27.5-33.2 \mathrm{pg}$ \\
\hline $\mathrm{MCHC}$ & 32.3 & $33.4-35.5 \mathrm{~g} / \mathrm{dL}$ \\
\hline RDW & 12.5 & $11.9-15.5 \%$ \\
\hline Plts & 342 & $150,000-400,000 / \mathrm{mL}$ \\
\hline MPV & 10.7 & 9.4-12.3fL \\
\hline Neut\% & 46.5 & $40-60 \%$ \\
\hline Lymph\% & 41.8 & $20-40 \%$ \\
\hline Mono\% & 9.3 & $2-8 \%$ \\
\hline
\end{tabular}




\begin{tabular}{|c|c|c|}
\hline Eos $\%$ & 1.4 & $1-4 \%$ \\
\hline Baso\% & 0.9 & $0.5-1 \%$ \\
\hline Neut, Abs & 3.23 & $1500-8000$ cells $/ \mu \mathrm{L}$ \\
\hline Lymph, Abs & 2.91 & $1000-4800 \mathrm{mcL}$ \\
\hline Mono, Abs & 0.65 & $0.2-0.95 \times 10^{3} \mathrm{mcL}$ \\
\hline Eos, Abs & 0.1 & 30-350mcL \\
\hline Baso, Abs & 0.06 & $0-0.3 \mathrm{~mm}^{3}(\mathrm{k} / \mu \mathrm{l})$ \\
\hline Immature Gran\% & 0.1 & $0-0.5 \%$ \\
\hline Immat Gran, Abs & 0.01 & $0.10 \%$ \\
\hline BUN & 13 & $7-18 \mathrm{mg} / \mathrm{dL}$ \\
\hline $\mathrm{Na}$ & 141 & $136-145 \mathrm{mEq} / \mathrm{L}$ \\
\hline K & 3.8 & $3.5-5.0 \mathrm{mEq} / \mathrm{L}$ \\
\hline $\mathrm{Cl}-$ & 103 & $95-105 \mathrm{mEq} / \mathrm{L}$ \\
\hline HCO3- & 26 & $22-28 \mathrm{mEq} / \mathrm{L}$ \\
\hline Glu & 96 & $70-110 \mathrm{mg} / \mathrm{dL}$ \\
\hline Cret & 1.06 & $0.6-1.0 \mathrm{mg} / \mathrm{dL}$ \\
\hline $\mathrm{Ca}$ & 9.3 & $8.4-10.2 \mathrm{mg} / \mathrm{dL}$ \\
\hline $\begin{array}{l}\text { Estimated GFR, Black } \\
\text { Race }\end{array}$ & $>60$ & $>60 \mathrm{~mL} / \mathrm{min} / 1.73 \mathrm{~m}^{2}$ \\
\hline Anion Gap & 12 & $3-12 \mathrm{mEq} / \mathrm{L}$ \\
\hline TSH & 0.97 & $0.5-5.0 \mu \mathrm{U} / \mathrm{mL}$ \\
\hline AST & 16 & $8-40 \mathrm{U} / \mathrm{L}$ \\
\hline Alk Phos & 65 & $45-115 \mathrm{U} / \mathrm{L}$ \\
\hline T Bili & 0.2 & $0.1-1.0 \mathrm{mg} / \mathrm{dL}$ \\
\hline ALT & 12 & $8-40 \mathrm{U} / \mathrm{L}$ \\
\hline Alb & 4.5 & $3.5-5.5 \mathrm{~g} / \mathrm{dL}$ \\
\hline Protein & 6.5 & $6.0-7.8 \mathrm{~g} / \mathrm{dL}$ \\
\hline
\end{tabular}

\section{Discussion}

The patient presented here has an FMR1 premutation and was largely asymptomatic until her teenage years. Although it is unknown what subtype she of the premutation the patient had, the presence of POF suggests that she had the FXPOI subtype. At birth, premutation carriers can present with subtle clinical symptoms, including visual spatial deficits, greater sensitivity to sensory stimuli, and slight developmental delay [8,9]. Although this patient denied exhibiting these symptoms, they may have had a very subtle phenotype and were thus grossly missed. Studies have shown that pre-mutations were associated with increased risk for autism spectrum disorder and attention-deficit/hyperactivity disorder with males presenting more commonly than females [10]. This patient was never diagnosed with these conditions nor did she exhibit signs or symptoms during the interaction. Several studies have demonstrated an association between autism and eating disorders, possibly explaining the presence of anorexia that this patient began to experience in her teenage years that potentially worsened with increased Ducalax use [11,12].

The patient had noted that she had a longstanding history of anxiety and depression. Studies have shown that psychological disorders are the most common conditions affecting carriers in childhood. Between the ages of 5 and 23, anxiety disorders, including Generalized Anxiety Disorder, Specific Phobia, Social Phobia and Obsessive-Compulsive Disorder, are the most common conditions experienced [13,14]. Developmentally, carriers have a cerebellar and brainstem volume decrease compared to the general population suggesting the need for earlier intervention in these individuals [15]. Studies performed in adult carriers with psychological symptoms have also demonstrated decreased amygdala function resulting in decreased emotional attachment and understanding largely attributed to reduced cognitive function [16]. This may help to explain the patient's life choices, including addictions and tanner bed use.

Depression is another psychological manifestation that affects these individuals more so than the general population, where studies have demonstrated a bell-shaped association between the number of CGG repeats and severity of depressive symptoms, where 70-100 repeats confers the greatest risk, while the repeats on the lower and higher ends of the premutation confers lower risks of psychiatric symptoms [17-19]. Patients with a medium number of CGG repeats (85-110) had the highest-level depressive symptoms [20]. These symptoms tend to manifest in females earlier than males attributed largely to greater sensitivity to life's stressors, such as childbirth and parenting [19]. However, depression does occur in female carriers even before these stressors as well. This patient's depression appeared to be well controlled with Sertraline as she denied suicidal and/or homicidal inclinations and exhibited low scores on GAD-7 and PHQ-9 tests. However, she may still suffer from 
atypical depression (leaden paralysis, mood reactivity, hyperphagia of recreational drugs, and longstanding interpersonal rejection sensitivity) as she was positive for hyperphagia of laxatives and longstanding interpersonal rejection sensitivity [21,22].

Studies have demonstrated that the cognitive decline associated with Fragile $\mathrm{X}$ and associated gross brain changes can also contribute to the manifestation of anorexia as patients can display a lack of awareness and/or ability to control the progression of this condition just as this patient had alluded [23-25]. Patients are also more prone to developing addictive disorders [26-28]. Based on her history, she turned to laxatives initially to manage unexplained bouts of chronic constipation but eventually developed an addiction to them that worsened an underlying anorexia according to the patient. Although the patient looked cachectic and slightly dehydrated on exam, her vital signs and labs were largely within normal limits except for initial hypotension that resolved upon retake toward of the encounter (Table 1) and a slightly elevated Creatinine (Table 2). Although the patient did exhibit hyperreflexia on exam, this cannot be explained by electrolyte abnormalities.

Studies have demonstrated an association between Fragile X Syndrome and substance abuse [28]. Although there are only a few studies, they indicate that the substance preference is contingent on the environment and accessibility of the patient to it $[26,28]$. Studies that have sought to evaluate this on the molecular level have attributed this to the extent of CGG repeats and their association with cognitive impairment resulting in poor decision-making [29]. Additionally, the extent of CGG repeats has contributed to gross brain changes which may help to explain the increased propensity for addiction in this patient population as well [6]. The increased use of addictive substances, like alcohol, in carriers can worsen their underlying neurological condition present at baseline [28]. Short term memory can also be affected contributing to worsening neurological function and act as a nidus to worsen addictive symptoms [30]. Overall, this case report uniquely discusses the vast breadth of symptoms that this Fragile $\mathrm{X}$ female carrier phenotypically expressed. Her presentation showcases the importance of early genetic screening and childhood intervention to control symptomatic progression and the high risk for addiction and depression that can exacerbate underlying disease and comorbidities.

\section{References}

1. Hagerman RJ (2005) Fragile X syndrome. Management of Genetic Syndromes.

2. Hagerman RJ, Leehey MA, Hall DA, Levine RA, Brunberg JA, et al. (2004) Penetrance of the fragile $\mathrm{X}$-associated tremor/ataxia syndrome in a premutation carrier population. JAMA 291(4): 460-469.

3. Rodriguez RL, Madrigal I, Pagonabarraga J, Xunclà M, Badenas C, et al (2009) Penetrance of FMR1 premutation associated pathologies in fragile X syndrome families. Eur J Hum Genet 17(10): 1359-1362.

4. Grigsby J, Brega AG, Jacquemont S, Loesch DZ, Leehey MA, et al. (2006) Impairment in the cognitive functioning of men with fragile X-associated tremor/ataxia syndrome (FXTAS). J Neurol Sci 248(1-2): 227-233.
5. Bourgeois JA, Cogswell JB, Hessl D, Zhang L, Ono MY, et al. (2007) Cognitive, anxiety and mood disorders in the fragile $\mathrm{X}$-associated tremor/ataxia syndrome. Gen Hosp Psychiatry 29(4): 349-356.

6. Wolff JJ, Hazlett HC, Lightbody AA, Reiss AL, Piven J, et al. (2013) Repetitive and self-injurious behaviors: Associations with caudate volume in autism and fragile X syndrome. J Neurodev Disord 5(1): 12.

7. Gallagher A, Hallahan B (2012) Fragile X-associated disorders: A clinical overview. Journal of Neurology 259(3): 401-413.

8. Wheeler AC, Sideris J, Hagerman R, Kravis EB, Tassone F, et al. (2016) Developmental profiles of infants with an FMR1 premutation. J Neurodev Disord 8: 40.

9. Gallego PK, Burris JL, Rivera SM (2014) Visual motion processing deficits in infants with the fragile X premutation. J Neurodev Disord 6(1): 29.

10. Clifford S, Dissanayake C, Bui QM, Huggins R, Taylor AK, et al. (2007) Autism spectrum phenotype in males and females with fragile $\mathrm{X}$ full mutation and premutation. J Autism Dev Disord 37(4): 738-747.

11. Westwood H, Tchanturia K (2017) Autism spectrum disorder in anorexia nervosa: An updated literature review. Curr Psychiatry Rep 19(7): 41.

12. Nickel K, Maier S, Endres D, Joos A, Maier V, et al. (2019) Systematic review: Overlap between eating, autism spectrum, and attention-deficit/ hyperactivity disorder. Front Psychiatry 10: 708.

13. Cordeiro L, Abucayan F, Hagerman R, Tassone F, Hessl D, et al. (2015) Anxiety disorders in fragile $\mathrm{X}$ premutation carriers: Preliminary characterization of probands and non-probands. Intractable Rare Dis Res 4(3): 123-130.

14. Schneider A, Johnston C, Tassone F, Sansone S, Hagerman RJ, et al. (2016) Broad autism spectrum and obsessive-compulsive symptoms in adults with the fragile X premutation. Clin Neuropsychol 30(6): 929-943.

15. Wang JY, Hessl D, Hagerman RJ, Simon TJ, Tassone F, et al. (2017) Abnormal trajectories in cerebellum and brainstem volumes in carriers of the fragile X premutation. Neurobiol Aging 55: 11-19.

16. Hessl D, Wang JM, Schneider A, Koldewyn K, Le L, et al. (2011) Decreased fragile $\mathrm{X}$ mental retardation protein expression underlies amygdala dysfunction in carriers of the fragile $\mathrm{X}$ premutation. Biol Psychiatry 70(9): 859-865.

17. Johnston C, Eliez S, Friedman JD, Hessl D, Glaser B, et al. (2001) Neurobehavioral phenotype in carriers of the fragile X premutation. Am J Med Genet 103(4): 314-319.

18. Roberts JE, Bailey DB, Mankowski J, Ford A, Sideris J, et al. (2009) Mood and anxiety disorders in females with the FMR1 premutation. Am J Med Genet B Neuropsychiatr Genet 150B(1): 130-139.

19. Seritan AL, Bourgeois JA, Schneider A, Mu Y, Hagerman RJ, et al. (2013) Ages of onset of mood and anxiety disorders in fragile $\mathrm{x}$ premutation carriers. Curr Psychiatry Rev 9(1): 65-71.

20. Seltzer MM, Barker ET, Greenberg JS, Hong J, Coe C, et al. (2012) Differential sensitivity to life stress in FMR1 premutation carrier mothers of children with fragile X syndrome. Health Psychol 31(5): 612622.

21. Lojko D, Rybakowski JK (2017) Atypical depression: Current perspectives. Neuropsychiatr Dis Treat 13: 2447-2456.

22. Posternak MA, Zimmerman M (2001) Symptoms of atypical depression. Psychiatry Res 104(2): 175-181.

23. Grau A, Magallon NE, Faus G, Feixas G (2019) Cognitive impairment in eating disorder patients of short and long-term duration: A case-control study. Neuropsychiatr Dis Treat 15: 1329-1341.

24. Bostrom C, Yau SY, Majaess N, Vetrici M, Mohapel JG, et al. (2016) Hippocampal dysfunction and cognitive impairment in Fragile-X Syndrome. Neurosci Biobehav Rev 68: 563-574. 
25. Tamiya H, Ouchi A, Chen R, Miyazawa S, Akimoto Y, et al. (2018) Neurocognitive impairments are more severe in the binge-eating/ purging anorexia nervosa subtype than in the restricting subtype. Front Psychiatry 9: 138.

26. Arellano MJS, Lozano R, Tassone F, Hagerman RJ, Saldarriaga W, et al. (2016) Alcohol use dependence in fragile X syndrome. Intractable Rare Dis Res 5(3): 207-213.

27. Tan MMG, Dy JBS, Arellano MJS, Tassone F, Hagerman RJ, et al. (2019) Fragile X-associated neuropsychiatric disorders: A case report. Future Neurology 14(2): FNL14.
28. Muzar Z, Adams PE, Schneider A, Hagerman RJ, Lozano R, et al. (2014) Addictive substances may induce a rapid neurological deterioration in fragile X-associated tremor ataxia syndrome: A report of two cases. Intractable Rare Dis Res 3(4): 162-165.

29. Smith LN, Jedynak JP, Fontenot MR, Hale CF, Dietz KC, et al. (2014) Fragile $\mathrm{X}$ mental retardation protein regulates synaptic and behavioral plasticity to repeated cocaine administration. Neuron 82(3): 645-658.

30. Seritan A, Cogswell J, Grigsby J (2013) Cognitive dysfunction in FMR1 premutation carriers. Curr Psychiatry Rev 9(1): 78-84.

For possible submissions Click below:

Submit Article 